\title{
ENTRE SIGILO E TRANSPARÊNCIA: ANÁLISE DO PROCESSO DE ELABORAÇÃO DA LEI DE ACESSO À INFORMAÇÃO NO PODER EXECUTIVO FEDERAL (2006-2009)
}

\author{
BETWEEN SECRECY AND TRANSPARENCY: \\ ANALYSIS OF THE ELABORATION PROCESS OF THE \\ BRAZILIAN FREEDOM OF INFORMATION ACT IN THE \\ FEDERAL GOVERNMENT (2006-2009)
}

\author{
Francisco Eduardo Gonçalves ${ }^{a}$ \\ Georgete Medleg Rodrigues ${ }^{b}$ \\ Solano dos Santos Nascimentoc
}

\begin{abstract}
RESUMO
Introdução: A Lei de Acesso à Informação (LAl) foi debatida no âmbito do Poder Executivo Federal entre os anos de 2006 e 2009. O texto foi resultado do confronto entre posições divergentes sobre o alcance e a amplitude da transparência que se pretendia alcançar. Objetivo: Identificar e analisar a posição de diferentes agentes públicos, no âmbito do poder executivo federal, quanto a aspectos específicos da LAI buscando, nessa perspectiva, compreender o processo de discussão interna, identificando os setores mais inclinados ao sigilo e os mais associados à transparência. Metodologia: Os procedimentos metodológicos compreenderam a modalidade de pesquisa documental de registros arquivísticos do governo federal. Resultados: Foram identificados registros arquivísticos de setores do governo com restrições à proposta de uma nova lei de acesso. Constatou-se que o Comando do Exército foi o órgão que apresentou as objeções mais explícitas à ideia de criação de uma lei de acesso à informação, bem como o Ministério das Relações Exteriores. Conclusões: O projeto da LAl encontrou resistência principalmente de setores da administração pública que lidam com informações relacionadas à defesa nacional e às relações exteriores. Os pontos mais polêmicos foram as regras para classificação de documentos considerados sensíveis, incluindo categorias de sigilo, o prazo de proteção e a possibilidade ou não de perpetuação do sigilo por tempo indefinido.
\end{abstract}

Descritores: Lei de Acesso à Informação. Transparência pública. Sigilo informacional.

a Mestre em Comunicação pela Faculdade de Comunicação da Universidade de Brasília (UnB). E-mail: fleali68@gmail.com

b Doutorado em História Contemporânea pela Université de Paris (Paris IV - Sorbonne). Docente da École Nationale des Chartes, Paris. E-mail: medleg.georgete@gmail.com

c Doutor em Comunicação pela Universidade de Brasília (UnB). Docente da Universidade de Brasília (UnB). E-mail: nascimento@unb.br 
Governo federal.

\section{INTRODUÇÃO}

Os movimentos em prol da transparência governamental que ganharam relevo no cenário mundial nas duas últimas décadas, e alcançaram o Brasil, impulsionaram a edição de uma lei para assegurar o acesso à informação. A confluência de interesses para ampliar os dispositivos de prestação de contas do Estado emergiu, no entanto, de um processo permeado de enfrentamentos. A gênese da Lei de Acesso à Informação (LAI), sancionada em 2011, é o objeto de estudo deste artigo, parte de uma pesquisa em Mestrado no campo da Comunicação, que busca identificar e analisar, a partir de consulta a fontes arquivísticas, a posição de diferentes agentes públicos quanto a aspectos específicos da LAI, bem como entender o processo de discussão interna no governo federal entre setores partidários do sigilo e proteção das informações públicas em oposição aos que demandavam por maior transparência.

A Lei brasileira de acesso à informação tem sido objeto de estudos em várias áreas do conhecimento, incluindo a Ciência da Informação. Entretanto, poucos abordam o processo de construção da LAI. A grande maioria trata da sua implementação nas esferas federal, estadual ou municipal ou então em instituições públicas diversas.

Jardim (2013), por exemplo, em uma ampla pesquisa, analisou vários aspectos relativos à implementação da LAI em 15 estados da federação e o Distrito federal. Outro estudo, talvez o mais abrangente relacionado à implementação da LAI, é o de Michener, Moncau e Velasco (2015), cujo foco é a avaliação dos níveis de transparência no poder público. Assim, não faremos uma revisão de literatura exaustiva e no desenvolvimento desse artigo daremos destaque apenas àqueles trabalhos que tratam da elaboração da LAI.

O estudo considera a elaboração da LAl como parte do processo de formulação de uma política pública governamental de acesso às informações. Dessa maneira, verifica-se nos registros arquivísticos públicos o que expressa Francisco Fonseca (2016), ao afirmar que políticas públicas, na origem, são 
objeto de disputas e conflitos de interesses e "que a dinâmica das políticas públicas na perspectiva dos conflitos, das contendas e dos vetos se dá em sistemas políticos e regimes de governo concretos" (FONSECA, 2016, p. 408).

$\mathrm{O}$ artigo apresenta, inicialmente, os antecedentes históricos de leis de acesso em outras nações e o processo que deu origem à formatação da LAl brasileira. A partir de fontes arquivísticas, são expostas as iniciativas para elaboração da lei, bem como as posições de cada órgão pesquisado com relação ao anteprojeto enviado pelo Executivo federal ao Congresso Nacional em 2009.

Os procedimentos metodológicos consistiram em pesquisa documental, como enuncia Elisabete de Pádua (2012). O termo "documental" é, portanto, compreendido aqui na definição mais ampla que o considera como "toda base de conhecimento fixado materialmente e suscetível de ser utilizado para consulta, estudo ou prova" (PÁDUA, 2012, p. 69). Assim, são considerados na presente pesquisa os registros produzidos por órgãos do governo federal que participaram da elaboração da LAI como atas, pareceres, memorandos e até mesmo mensagens eletrônicas trocadas entre servidores públicos e que estão incluídas nos registros arquivísticos dos órgãos envolvidos na elaboração da lei.

Na mesma direção, Antonio Carlos Gil explica que, na pesquisa científica considera-se documento "não apenas os escritos utilizados para esclarecer determinada coisa, mas qualquer objeto que possa contribuir para a investigação de determinado fato ou fenômeno" (GIL, 2008, p. 147). O pesquisador aponta ainda que a pesquisa documental costuma recorrer ao que chama de "registros cursivos". Um exemplo dessa modalidade de registro é o documento produzido por agências de governo (GIL, 2008).

Os documentos analisados fazem parte do acervo dos ministérios que participaram do processo de elaboração da LAl. Esses ministérios estão expressamente citados na exposição de motivos enviada ao Congresso em anexo ao texto do projeto de lei. A consulta aos arquivos sobre o tema foi solicitada por um dos autores deste artigo utilizando a própria LAI.

Estão abrangidos na pesquisa os dados fornecidos pelos ministérios a partir de pedido de acesso a todos os registros que embasaram a redação do anteprojeto. Os documentos foram enviados pelos órgãos demandados por meio 
eletrônico no período de agosto a novembro de 2018. No caso do Ministério das Relações Exteriores, o acesso, a pedido do órgão, foi obtido a partir de visita agendada para pesquisa presencial entre os dias 3 e 6 de setembro de 2018 . Assim, o universo pesquisado limita-se aos dados oficialmente reconhecidos pela instituição produtora dos arquivos como relacionados à elaboração do anteprojeto, a maioria deles indexada nos próprios ministérios em processos eletrônicos e/ou físicos.

As datas-limites analisadas no presente artigo compreendem o período de 2006, ano em que surgem os primeiros registros de discussões no âmbito do governo federal sobre a elaboração de uma lei de acesso às informações públicas, até 2009, quando o anteprojeto foi finalizado e enviado ao Congresso Nacional para apreciação e votação. $O$ universo da pesquisa compreende os órgãos envolvidos diretamente na elaboração do texto. Esses serão apresentados segundo as manifestações que registraram formalmente $e$ constam em seus arquivos aos quais se teve acesso. Os órgãos são: Casa Civil da Presidência da República, Secretaria de Governo, Ministério da Defesa, Comandos da Marinha, Exército e Aeronáutica, Ministério da Justiça, AdvocaciaGeral da União (AGU), Controladoria Geral da União (CGU), Ministério do Planejamento, Ministério das Relações Exteriores e Secretaria de Comunicação da Presidência da República.

Nos documentos arquivados pelos órgãos públicos que compõem o universo da pesquisa buscamos identificar as forças que agiram para, ora abrir, ora fechar as possibilidades de acesso à informação, ou até mesmo impedir que a proposta do Executivo fosse enviada ao Congresso Nacional. É nesse sentido que os registros arquivísticos serão fundamentais para a compreensão das teses em jogo na elaboração da LAI, pois, segundo Rodrigues:

Os arquivos devem ser entendidos no seu duplo, paradoxal e conflituoso papel. Arquivos como memória, por conseguinte, testemunhas de acontecimentos ou de ações passadas, mas também como dispositivos no presente, portanto, muitas vezes, incômodos. (RODRIGUES, 2011, p. 257). 


\section{ANTECEDENTES HISTÓRICOS}

A primeira lei de acesso à informação de que se tem notícia surgiu na Suécia. Foi instituída ainda em 1766. O texto que inaugurou o tema, incorporado à Constituição daquele país, estava vinculado à imprensa. $O$ tema foi tratado na lei do direito à liberdade de imprensa, o The Freedom of Press Act (CHEN, 2017). Como observado por Nascimento, Rodrigues e Kramer (2015), a partir das afirmações de Öberg (2003), a lei sueca é "considerada uma das leis fundadoras da democracia sueca", sendo a primeira lei a considerar o direito de acesso aos documentos administrativos como um "princípio constitucional de primeira geração, herdado da filosofia do lluminismo" (ÖBERG, 2003 apud NASCIMENTO; RODRIGUES; KRAMER, 2015, p. 228).

O capítulo 2 dessa lei que aborda a "natureza pública de documentos oficiais" estabelece: "todo cidadão sueco tem o direito de ter livre acesso a documentos oficiais, a fim de incentivar a livre troca de opiniões e a disponibilidade de informações abrangentes"1.

$\mathrm{Na}$ Revolução Francesa de 1789, ainda que por um breve período, foi assegurado o acesso a documentos de arquivos públicos, como relata Rodrigues (2011). Lei editada em 1794 proclamou que documentos do "arquivo nacional" seriam de livre acesso a todos os cidadãos que os requeressem. Os documentos incluíam registros dos arquivos governamentais, administrativos, judiciais e eclesiásticos (DUCHEIN, 1983). Rodrigues aponta o retrocesso nesse aspecto, decorrente da restauração da monarquia que, no ano de 1856 altera o regulamento dos Arquivos Nacionais dessa vez atribuindo "ao diretor da instituição a prerrogativa de autorizar ou recusar o acesso aos acervos sob sua custódia" (RODRIGUES, 2011, p. 259).

$O$ segundo modelo de uma lei de acesso à informação propriamente dita só surgiria no século XX na Finlândia, cuja lei é de 1951, seguido dos Estados

\footnotetext{
${ }^{1}$ Tradução nossa a partir do original em inglês: "Art. 1. Every Swedish citizen shall be entitled to have free access to official documents, in order to encourage the free exchange of opinion and the availability of comprehensive information. Disponível em:

http://www.riksdagen.se/globalassets/07.-dokument-lagar/the-constitution-of-sweden160628.pdf. Acesso em: 01 out. 2018.
} 
Unidos que aprovaram o Freedom of Information Act (FOIA), em 1966 (MEIJER, 2014). A legislação americana acabou se tornando referência para outros países e está, em grande medida, na origem do texto legal discutido e aprovado no Brasil 45 anos mais tarde (MINISTÉRIO DA JUSTIÇA, 2006).

$\mathrm{Na}$ década de 1970, quatro países aprovaram leis similares. Na década de 1980, outros seis. Já na década de 1990, surgiram novas leis em 19 países. Entre 2000 e 2010, o mesmo correu em outros 55 países. De 2011 a 2016, foram aprovados mais 24 instrumentos legais, entre elas a Lei de Acesso à Informação (LAI) do Brasil, de 20112.

A instituição de leis de acesso, a partir do século XX, parte do disposto no artigo 19 da Declaração Universal dos Direitos Humanos (ONU, 1948), que assegura a todo o indivíduo "liberdade de opinião e de expressão, o que implica o direito de não ser inquietado pelas suas opiniões e o de procurar, receber e difundir, sem consideração de fronteiras, informações e ideias".

\section{A ORIGEM DA LAI}

Em 2006, mesmo ano em que o país homologou a Convenção das Nações Unidas contra a Corrupção, o governo brasileiro começou a elaborar o anteprojeto da lei de acesso (CUNHA FILHO; XAVIER, 2014). A elaboração de uma lei surge como reação tardia ao que já estava previsto na Constituição Federal (CF) de 1988. O artigo $5^{\circ}$ inciso XXXIII da CF estabelece como direito fundamental de todo cidadão receber das administrações públicas "informações de seu interesse particular, ou de interesse coletivo ou geral, que serão prestadas no prazo da lei, sob pena de responsabilidade, ressalvadas aquelas cujo sigilo seja imprescindível à segurança da sociedade e do Estado".

A ideia de uma lei brasileira de acesso vinha sendo defendida por movimentos da sociedade civil desde o início dos anos 2000. Entre as entidades envolvidas estava a Associação Brasileira de Jornalismo Investigativo (Abraji) que, organizou, ainda em 2003, o Seminário de Direito de Acesso à Informação

\footnotetext{
${ }^{2}$ Os dados fazem parte de levantamento contido no Global Right to Information Rating. Disponível em: https://www.rti-rating.org/historical/. Acesso em: 01 out. 2018.
} 
Pública. Esse encontro levou à formação do Fórum Brasileiro para o Direito de Acesso à Informação Pública, composto por representantes de organizações não-governamentais envolvidas no tema (BARROS, 2017). A mesma autora relata que a Transparência Brasil teve também relevante participação nesse processo, informando que o então representante da entidade, Claudio Weber Abramo, foi o responsável por levar o tema para discussão no Conselho da Transparência Pública e do Combate à Corrupção. As discussões estão registradas nas atas do conselho entre 2005 e 2009.

Paes (2011) reserva uma seção de artigo para uma breve síntese dos trâmites legislativos relacionados ao projeto de lei que resultou na LAl, bem como aos atores institucionais que participaram desse processo. Para ela, "existiram de fato análise e debate democrático sobre o acesso à informação" e que "o texto final da Lei de Acesso à Informação brasileira finalmente reuniu em um só diploma as principais disposições sobre o assunto" (PAES, 2011, p. 414). Na perspectiva de Paes, foi significativa a revogação das "normas conflitantes" no projeto aprovado.

Familiares de mortos e desaparecidos políticos durante a ditadura militar e grupos interessados na abertura de arquivos desse período também se associaram na defesa de uma lei de acesso à informação. Esse grupo, com apoio do Ministério Público Federal em São Paulo, chegou a redigir uma minuta de lei de acesso que foi encaminhada ao Ministério da Justiça (MINISTÉRIO DA JUSTIÇA, 2006).

Antes disso, o movimento em busca de acesso aos arquivos da ditadura já havia se deparado com dificuldades, no final da década de 1990, para obter informações no âmbito da Comissão de Mortos e Desaparecidos que, como relata Rodrigues (2007), pode contar apenas com acervo do antigo Dops nos estados do Rio de Janeiro e São Paulo, bem como arquivos públicos do Paraná e de Pernambuco, cujo recolhimento aos arquivos públicos daqueles estados havia sido autorizado pelos governos do Paraná e São Paulo. No início dos anos 2000, foram instaurados inquéritos em São Paulo, Paraná e Brasília para tentativa de localização dos mortos na Guerrilha do Araguaia. Em 2003, uma primeira decisão judicial proferida no Distrito Federal determinou acesso a documentos sigilosos que fizessem referência ao episódio ocorrido durante o regime militar (RODRIGUES, 2007). 
Assim, a busca por documentos da ditadura está diretamente associada ao processo de discussão da Lei de Acesso à Informação. No mesmo dia em que sancionou a LAI (Lei 12.527), em novembro de 2011, a então presidente Dilma Rousseff também sancionou lei que criou a Comissão Nacional da Verdade (Lei 12.528).

Entre a redação original da primeira versão produzida no âmbito do governo federal e o texto final do anteprojeto-de-lei da Lei de Acesso à Informação passaram-se três anos. Somente em 15 de maio de 2009, na gestão do então presidente Luiz Inácio Lula da Silva, foi enviada ao Congresso a mensagem 316/2009. Na Câmara, o texto que ganhou a indexação de PL $5.228 / 2009$ continha a proposta do Executivo para criar uma nova lei3. Na época, já estava em tramitação na Câmara dos Deputados projeto de autoria do deputado Reginaldo Lopes (PT-MG) tratando do tema (BRASIL, 2003). O PL 219 do parlamentar foi apresentado em $2003^{4}$ e aprovado pelas Comissões de Trabalho, de Administração e Serviço Público (CTASP) e de Constituição e Justiça e de Cidadania (CCJC) em 2004.

O projeto ficou parado até 2009, quando chegou ao Parlamento o texto do governo que foi apensada à proposta do deputado. Só então o assunto começa a tramitar em regime de urgência, o que garante mais celeridade na apreciação do texto legislativo. O projeto foi aprovado em 13 de abril de 2010 pela Câmara dos Deputados (BRASIL, 2010). Remetido ao Senado, passou a enfrentar restrições (REIS, 2014 apud CUNHA FILHO; XAVIER, 2014). Presidente da Comissão de Relações Exteriores, o ex-presidente Fernando Collor, senador por Alagoas, se autonomeou relator da proposta que ganhou o número de PLC 41/2010. Nessa condição, o senador apresentou uma versão mais restritiva, mantendo, por exemplo, a renovação do sigilo por tempo indeterminado dos documentos classificados como ultrassecretos (COLLOR, 2011).

\footnotetext{
${ }^{3}$ Disponível em:

http://www.camara.gov.br/proposicoesWeb/fichadetramitacao?idProposicao=434566. Acesso em: 03 out. 2018.

4 Disponível em: http://www.camara.gov.br/proposicoesWeb/fichadetramitacao?idProposicao=105237. Acesso em: 03 out. 2018.
} 
No dia 26 de outubro de 2011, o plenário do Senado Federal aprovou o texto original da Câmara, rejeitando a proposta do senador Fernando Collor de Mello. Na versão aprovada, os documentos ultrassecretos, que contêm as informações consideradas mais sensíveis, estavam protegidos por 25 anos, renováveis apenas uma vez. O projeto foi sancionado pela então presidente Dilma Rousseff e publicado em edição extra do Diário Oficial em 18 de novembro de 2011. O texto sancionado estabeleceu que a lei entraria em vigor seis meses depois, em maio de 2012.

\section{A GÊNESE DA LAI NO ÂMBITO DA ADMINISTRAÇÃO PÚBLICA FEDERAL: O QUE DIZEM OS ARQUIVOS?}

Como dito anteriormente, os documentos arquivados por órgãos do governo federal fornecem pistas de como se deu a elaboração formal do texto da LAl brasileira. Os registros pesquisados fazem parte dos arquivos dos seguintes órgãos da administração pública federal: Casa Civil da Presidência da República, Secretaria de Governo, Ministério da Defesa, Comandos da Marinha, Exército e Aeronáutica, Ministério da Justiça, Advocacia Geral da União (AGU), Controladoria Geral da União (CGU), Ministério do Planejamento, Ministério das Relações Exteriores e Secretaria de Comunicação da Presidência da República5.

Os registros consultados apontam que na gênese do projeto da LAl estão dois textos produzidos na esfera governamental. Em 2006, ano em que o Brasil homologou a convenção da ONU contra a corrupção, o Ministério da Justiça e a CGU esboçaram duas propostas de anteprojetos de lei. Há indicações nos referidos documentos sobre discussões ocorridas na Casa Civil com participação dos ministérios envolvidos no tema.

Há ainda uma terceira versão de texto elaborada pelo Ministério Público Federal (MPF) no mesmo ano. Essa proposta foi redigida a partir de requerimentos apresentados ao MPF por grupos de familiares de mortos e

\footnotetext{
${ }^{5}$ Com as mudanças promovidas pela gestão do Presidente Jair Bolsonaro, em janeiro de 2019, houve a fusão entre alguns desses órgãos e/ou incorporação de funções. Para a estrutura atual do poder Executivo federal. Disponível em: http://www.brasil.gov.br/. Acesso em: 17 abr. 2019.
} 
desaparecidos políticos durante o regime militar. O texto foi encaminhado à Presidência da República e também ao Ministério da Justiça e também aparece em arquivos da CGU e do Ministério da Defesa. O presente artigo se concentra apenas nas propostas de produção do Executivo.

O primeiro registro arquivístico sobre elaboração de anteprojeto de lei relacionado ao tema data de 29 de junho de 2006. Trata-se da Nota Técnica 68/2006 do Ministério da Justiça. O documento, acompanhado de mensagem do então ministro da Pasta Márcio Thomaz Bastos à Presidência da República, explica a origem da proposta. Segundo a nota, o texto foi elaborado a partir de recomendação feita pela Organização dos Estados Americanos - OEA, na $9^{\underline{a}}$ Reunião da Comissão de Peritos, realizada em Washington, de 27 de março a $1^{\circ}$ de abril de 2006.

Apesar de considerar que o Brasil tinha na época um arcabouço legal "satisfatório", a Comissão sugerira que o país "avaliasse a conveniência de integrar e sistematizar em um só diploma normativo as disposições que garantem o acesso à informação pública" (MINISTÉRIO DA JUSTIÇA, 2006). 0 texto proposto no Ministério da Justiça tinha 51 artigos, enfatizava os aspectos arquivísticos, tratava do instituto jurídico do habeas data e mantinha regra de proteção de documentos sigilosos por no máximo 30 anos, com direito à prorrogação por tempo indeterminado. $O$ esboço tinha a seguinte ementa: "Dispõe sobre documentos públicos e privados, instituições arquivísticas públicas, acesso e sigilo de documentos públicos e habeas data."6

No mesmo ano, outra iniciativa foi gestada na CGU. No Aviso 745/2006 de 8 de dezembro de 2006, a CGU enviou à então ministra da Casa Civil Dilma Rousseff sua proposta de anteprojeto. O texto foi elaborado pela CGU depois de discussão com entidades da sociedade civil no âmbito do Conselho da Transparência Pública e Combate à Corrupção (CGU, 2007). A proposta já foi concebida como uma lei de acesso à informação, mas numa versão sucinta com apenas 12 artigos. Segundo o documento, estabeleceu-se prazo limite, não

\footnotetext{
${ }^{6} \mathrm{O}$ instituto do habeas data está previsto no art. $5^{\circ}$, inciso LXXII, da CF de 1988 , sendo regulamentado pela Lei o $9.507 / 97$. Essa lei regula o direito de acesso a informações e disciplina o rito processual do habeas data para conhecimento ou retificação relativamente aos dados da pessoa do impetrante.
} 
prorrogável, de 30 anos para proteção de documentos e servidores que negassem acesso de maneira indevida poderiam ser enquadrados por crime de improbidade administrativa.

Em que pese a possibilidade de a proposta legal ter sido debatida internamente no governo desde o envio das propostas das duas Pastas à Presidência da República em 2006, nos arquivos disponíveis não foram encontrados registros de reuniões frequentes. Os documentos têm lacunas temporais e o trabalho para a redação da proposta de lei, segundo esses registros, foi conduzido conforme indicado a seguir:

Quadro 1 - Cronologia das propostas até a redação final do projeto de lei

\begin{tabular}{|l|l|}
\hline Ano & \multicolumn{1}{|c|}{ Etapa do trabalho de discussão e redação } \\
\hline 2006 & Elaboração de proposta de anteprojeto de lei pela CGU \\
\hline & $\begin{array}{l}\text { Elaboração de proposta de anteprojeto de lei pelo Ministério da } \\
\text { Justiça }\end{array}$ \\
\hline 2007 & $\begin{array}{l}\text { Elaboração de proposta de anteprojeto de lei pelo Ministério } \\
\text { Público Federal } \\
\text { redação do anteprojeto }\end{array}$ \\
\hline 2008 & Rentativa de fechar texto final em dezembro de 2007 \\
\hline & Discussão adiada a pedido do Ministério da Defesa \\
\hline 2009 & Medanifestações das Forças Armadas Casa Civil para discussão do texto do anteprojeto \\
\hline & Remessana do projeto de lei ao Congresso Nacional \\
\hline
\end{tabular}

Fonte: Elaboração própria a partir de documentos do arquivo do governo federal.

Documentos da Casa Civil registram que no final de 2007 foi feita a primeira tentativa de concluir o texto do projeto. No dia 11 de dezembro de 2007 foram expedidos ofícios a vários órgãos, solicitando comparecimento ao Palácio do Planalto para discutir, no dia 17 de dezembro daquele ano, a redação final do projeto. Nos arquivos do Ministério da Defesa foi identificado ofício do dia 12 de dezembro solicitando que os comandos do Exército, da Marinha e da 
Aeronáutica analisassem o esboço que havia sido enviado pela Casa Civil (MINISTÉRIO DA DEFESA, 2007-2008). O comunicado registra que, até aquela data, a Defesa não tinha sido chamada a participar das discussões para elaboração do texto. Três dias antes da reunião na Presidência da República, o Ministério da Defesa enviou Ofício oㅜ 12.770 à Casa Civil solicitando o adiamento da discussão. A conclusão do texto foi postergada e os entendimentos sobre a redação do projeto continuaram em 2008, estendendo-se até maio de 2009, quando a proposta foi enviada ao Congresso.

\section{SIGILO E DISSENSO}

Em artigo sobre o processo de elaboração da LAl envolvendo tanto as discussões internas, como os debates ocorridos no Congresso, Temístocles Murilo de Oliveira Júnior e Cristiano Fonseca Monteiro (2018) apontam quatro principais controvérsias envolvendo os atores que participaram do processo de criação da nova lei: o escopo da LAl; o prazo máximo de sigilo de documentos; a autonomia para coordenar a implementação da lei; a independência para ter a palavra final em caso de recursos decorrentes de pedidos de acesso negados. $O$ presente estudo encontrou indicativos das divergências apontadas pelos dois pesquisadores no corpus pesquisado.

Nos arquivos do Ministério das Relações Exteriores, consultados com autorização do órgão, foram localizados dois documentos de autoria da Subchefia para Assuntos Jurídicos da Casa Civil da Presidência da República. Esses documentos sistematizam as posições dos diferentes órgãos em relação a temas mais sensíveis da proposta de projeto. O primeiro tem o título "Anteprojeto de Lei de Acesso à Informação". O segundo, "Arquivos da ditadura"?.

\footnotetext{
7 Esse documento faz um breve histórico sobre o processo de abertura de arquivos vinculados ao período da ditadura militar. Divide o processo em quatro fases. A primeira trata do envio de documentos do extinto Serviço Nacional de Informação (SNI) para o Arquivo Nacional em 2005. $\mathrm{Na}$ segunda fase tratou de levantamento de acervo no Itamaraty, Polícia Federal e um grupo de ministérios. A terceira tratou de acesso a documentos das Forças Armadas entre 2006 e 2008 culminando com remessa ao Ministério Público Federal de pedido de investigação para apurar destruição de arquivos. A quarta fase, proposta na ocasião da elaboração do documento, seria uma chamada pública para entrega de documentos em poder de particulares.
} 
O documento sobre a LAI traz explicações sucintas do esboço do anteprojeto e contém quadros sintéticos comparativos com os pontos principais da proposta, além de indicação das versões que as diferentes áreas de governo sugeriram, como mostra a Figura 1. O tópico 5 do documento trata dos "prazos de classificação" para documentos sigilosos.

\section{Figura 1 - Fac-símile de documento da Casa Civil sobre prazo de proteção de documentos sigilosos}

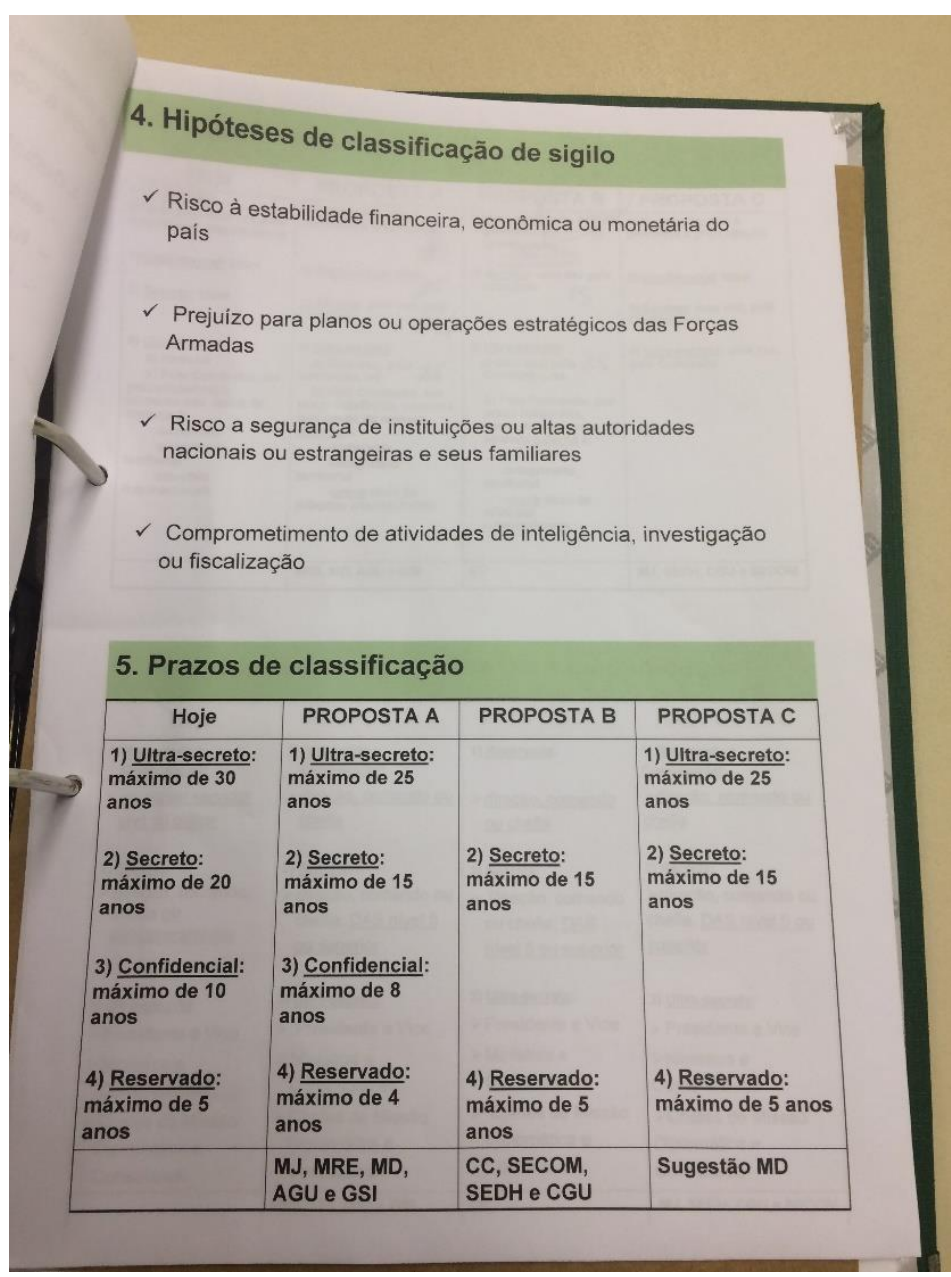

Fonte: Subchefia para Assuntos Jurídicos da Casa Civil - Acervo do Ministério das Relações Exteriores

Um quadro identifica três propostas denominadas pelas letras $A, B$ e $C$. Na proposta $A$, o prazo máximo de proteção para documentos ultrassecretos (o mais alto grau de proteção na legislação brasileira) é de 25 anos; para documentos secretos, 15 anos; para confidenciais, 8 anos; e 4 anos para os reservados. Concordavam com esse limite os ministérios da Justiça, Defesa, Relações Exteriores, Advocacia-Geral da União (AGU) e Gabinete de Segurança 
Institucional (GSI). Na proposta $\mathrm{B}$, há referência apenas a 15 anos de prazo para documentos secretos e 5 anos para os reservados, ideia com adesão da Casa Civil, Secretaria de Comunicação (Secom), Secretaria de Direitos Humanos e CGU. Na proposta C, os ultrassecretos teriam também 25 anos de proteção, os secretos 15 anos; e os reservados 5 anos; e não há referência a documentos confidenciais ${ }^{8}$. Essa proposta é atribuída a uma sugestão de aparente conciliação feita pelo Ministério da Defesa. Esses prazos da proposta C são os mesmos que foram definidos no projeto de lei 5.228 encaminhado pelo Executivo em 2009 (BRASIL, 2009, p. 6), e são os que, hoje, estão no artigo 24 da Lei de Acesso à Informação (BRASIL, 2011).

No item 6 do mesmo documento, sob o título "Possibilidade de prorrogação" são apresentadas as propostas para renovação do prazo de proteção dos documentos sigilosos, como mostra a Figura 2. Também são três as sugestões. Na proposta $A$, os documentos reservados não teriam prazo de proteção prorrogado; confidenciais também não; secretos poderiam ser renovados por uma vez por comissão interministerial; ultrassecretos com direito a uma renovação ou ainda por tempo indeterminado quando tratem de "ameaça externa: à soberania, integridade territorial e grave risco às relações internacionais". A proposta tinha apoio do Itamaraty, Defesa, AGU e GSI. Na proposta $B$, defendida pela Casa Civil, documentos reservados não teriam proteção prorrogada; os secretos uma única vez pela comissão interministerial; e os ultrassecretos nos mesmos moldes da proposta A. A proposta C argumentava que documentos reservados e confidenciais não teriam sigilo renovado; secretos e ultrassecretos apenas uma vez. Essa proposta tinha apoio do Ministério da Justiça, Direitos Humanos, CGU e Secom.

\footnotetext{
${ }^{8}$ Até a promulgação da LAI, as categorias de documentos sigilosos estavam indicadas na Lei 8.159, a Lei de Arquivos, de 1991, no seu Art. 5o: Os dados ou informações sigilosas serão classificados em ultra-secretos [sic], secretos, confidenciais e reservados, em razão do seu teor ou dos seus elementos intrínsecos. O Decreto 4.553, de 2002, reafirmou essas categorias estabelecendo os prazos de sigilo para cada uma delas.
} 
Figura 2 - Fac-símile de documento da Casa Civil sobre propostas de prorrogação de prazo de sigilo

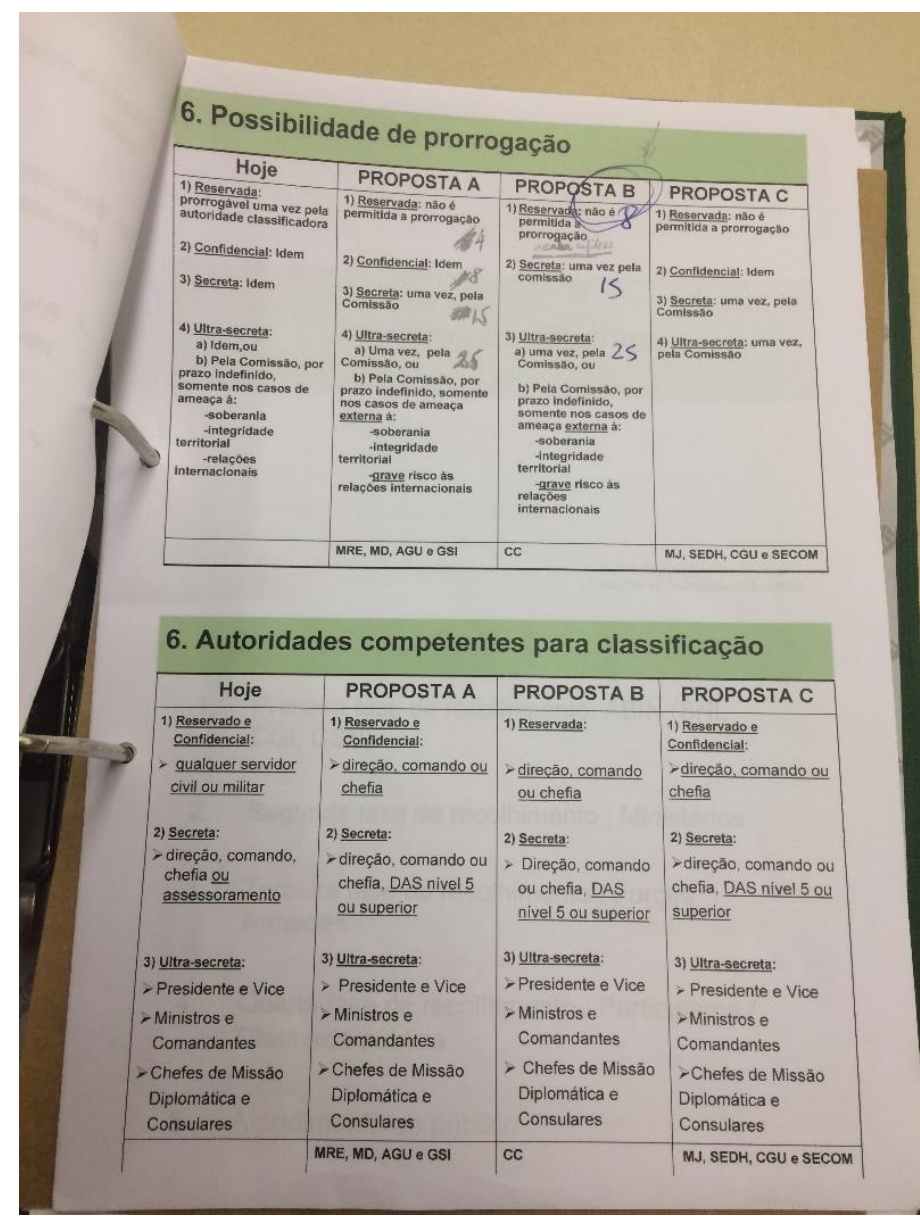

Fonte: Subchefia para Assuntos Jurídicos da Casa Civil - Acervo do Ministério das Relações Exteriores

O texto final encaminhado pelo governo ao Congresso em 2009 estabeleceu, no artigo 30, que os ultrassecretos poderiam ter o sigilo prorrogado por "prazo determinado, enquanto o seu acesso ou divulgação puder ocasionar ameaça externa à soberania nacional ou à integridade do território nacional ou grave risco às relações internacionais do país" (BRASIL, 2009, p. 11). Na LAI, o assunto é tratado no artigo 35 e tem essa mesma redação. Mas há um parágrafo, incluído durante apreciação pelo Legislativo, limitando a prorrogação a apenas uma vez (BRASIL, 2011).

$\mathrm{Na}$ pesquisa, os órgãos disponibilizaram acervos que contêm manifestações até o final de 2008. Não foram localizados pareceres dos órgãos no mesmo ano do envio do texto ao Congresso em maio de 2009. A maioria dos registros encontrados na pesquisa documental indica um posicionamento dos 
órgãos em relação ao dispositivo legal sem oposição clara à criação de uma nova lei, ou seja, os documentos registram contribuições formais ao texto em elaboração.

Foi encontrada oposição explícita em um documento do Exército. No dia 9 de outubro de 2008, o ofício no 543 enviado ao Ministério da Defesa lista mais de 30 pontos do texto que, na avaliação do Gabinete do Comando do Exército, não poderiam ser mantidos com a redação formulada na Casa Civil. No ofício de cinco páginas, o então chefe de gabinete do comandante, o general de Divisão Joaquim Silva e Luna, apresenta sugestões de alteração, mas conclui com manifestação taxativa: "...a Força é de posição CONTRÁRIA [sic] à transformação do Anteprojeto de Lei em Projeto de Lei a ser enviado ao Congresso Nacional" (EXÉRCITO, 2008, p. 5).

\section{Figura 3 - Fac-símile de documento do Comando do Exército}

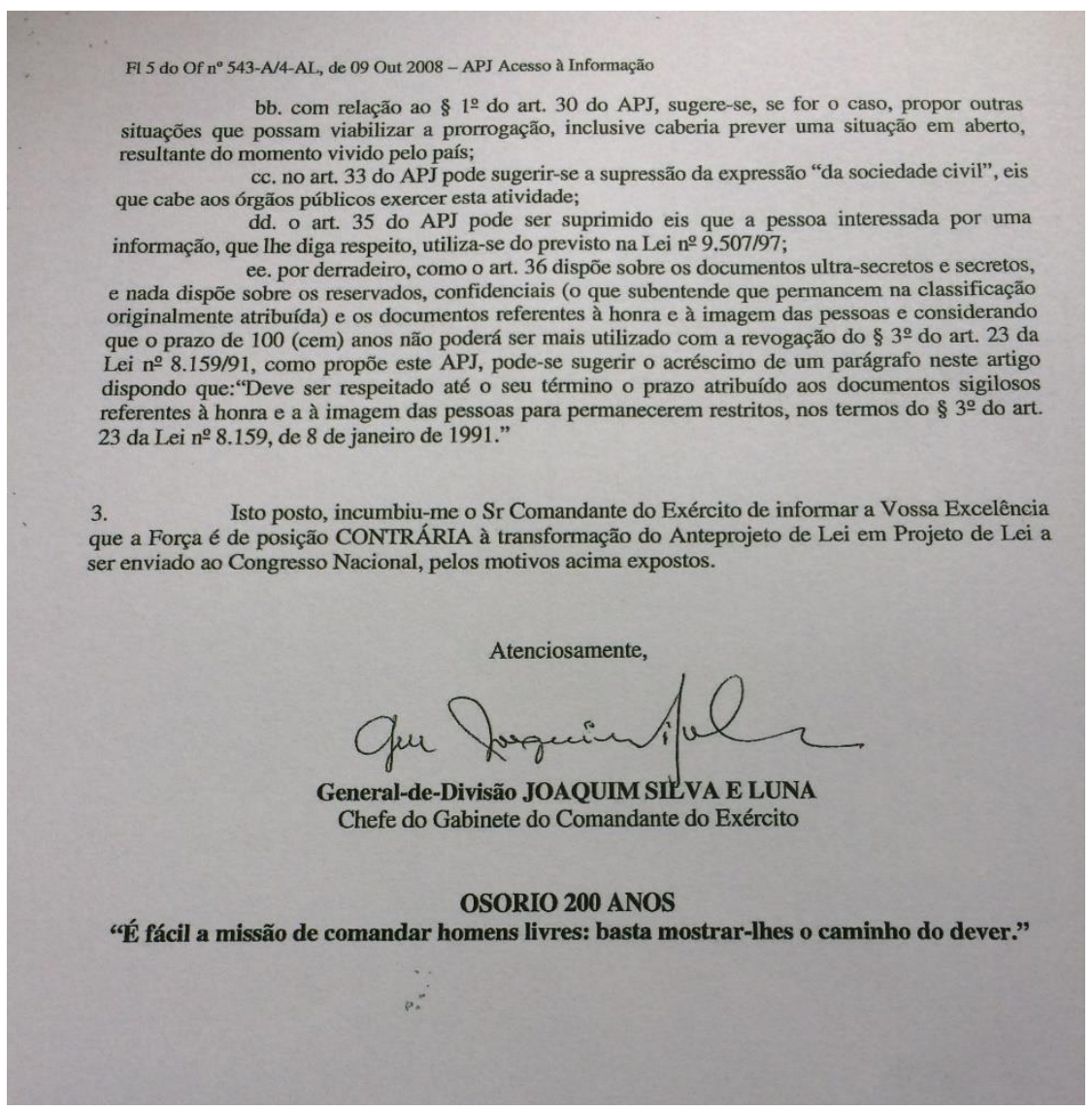

Fonte: Acervo do Comando do Exército.

Também no final de 2008, os comandos da Marinha e da Aeronáutica elaboraram documentos com recomendações de alterações no texto. As 
sugestões focam em aspectos ligados à preocupação de a nova lei permitir acesso a documentos sigilosos que, uma vez públicos, pudessem colocar em risco a defesa nacional. Não houve, no entanto, manifestação categórica de oposição ao envio do texto ao Congresso Nacional.

No caso da Aeronáutica, o Ofício no 116 de 23 de setembro de 2008 enviado ao Ministério da Defesa lista oito pontos nos quais o comando solicita alterações no texto do anteprojeto da LAI (AERONÁUTICA, 2008). Entre eles está um pedido para incluir na lista de temas que deveriam ter o sigilo preservado aqueles relacionados às investigações conduzidas pela Aeronáutica em casos de acidentes aéreos. A FAB também solicitou suprimir o trecho que obrigava a divulgação da relação de documentos classificados. A Aeronáutica queria também que os registros com grau de confidencial ou reservado pudessem ter 0 prazo de sigilo prorrogado por uma vez. Sugeriu, ainda incluir o Ministério Público na lista de entidades que poderiam compor o conselho que iria zelar pelo cumprimento da lei.

Na Marinha, o parecer 52/2008 resume as sugestões do comando para alteração da lei. Com data de 23 de setembro daquele ano, o documento registra até pedido de correção gramatical no texto do anteprojeto. Em relação ao conteúdo propriamente dito, a Marinha aponta riscos de submeter a uma comissão interministerial o poder de validar classificação de documentos secretos e ultrassecretos.

Vislumbra-se um aumento considerável da probabilidade de vazamento de assuntos sensíveis, afetos ao Estado, considerando o aumento do número de pessoas com acesso aos temas classificados como Secretos e Ultrassecretos, as quais até então não possuíam a necessidade de conhecê-los. (MARINHA, 2008, p. 2).

A Marinha também faz referência a uma versão do texto do anteprojeto que previa apenas dois graus de sigilo para documentos e alerta para o risco de uma valorização inadequada das informações. "Se houver dúvida quanto à gradação do sigilo, a autoridade pública, naturalmente, irá optar pela classificação de grau mais elevado" (MARINHA, 2008, p. 3).

Sobre o mesmo assunto, a Marinha ainda alerta para o fato de que temas relacionados ao emprego das Forças Armadas em caso de conflito poderão estar 
expostos. A Força manifestou ainda preocupação com eventual possibilidade de vir a público documento relacionado ao Programa Nuclear da Marinha.

O Ministério das Relações Exteriores também apresentou sugestões de alterações na minuta de anteprojeto, manifestando preocupação em relação à divulgação de documentos sensíveis. O Memorando no. 37 de 29 de julho de 2008 registra realização de uma reunião na Casa Civil seis dias antes com a finalidade de finalizar o texto do anteprojeto. Há menção de que a referida reunião foi comandada pela subchefe da Casa Civil e que ocorreu na sequência de um outro encontro com a participação da então ministra Dilma Rousseff.

O memorando relata que o anteprojeto até então acordado foi debatido por dois anos e lista dois pontos de maior divergência: prazos máximos de classificação de documentos sigilosos e possibilidade de prorrogação desses prazos. No documento, está registrado que houve uma tentativa de negociação que vinculou os dois pontos.

O Itamaraty declara ter aceitado a redução dos prazos de sigilo dos documentos classificados, mas com intenção de manter a possibilidade de renovação desses prazos. Assim, para documentos ultrassecretos o prazo de 30 poderia cair para 25 anos; secretos de 20 para 15 anos; confidenciais de 10 para 8 anos; e reservados de 5 para 4 anos (MINISTÉRIO DAS RELAÇÕES EXTERIORES, 2008).

O mesmo memorando explicita ainda a correlação de forças internas no governo na discussão do texto da lei. O Itamaraty narra que, com apoio do Ministério da Defesa e do Gabinete de Segurança Institucional (GSI), foi incluído no texto a possibilidade de prorrogação indefinida dos documentos ultrassecretos. "A inclusão foi feita a despeito de forte oposição por parte do Ministério da Justiça e, especialmente, da Secretaria Especial de Direitos Humanos..." (MINISTÉRIO DAS RELAÇÕES EXTERIORES, 2008, p. 2).

O memorando interno foi direcionado à Subsecretaria-Geral do Serviço Exterior do Itamaraty e, depois levado a conhecimento do ministro de Relações Exteriores, como expresso em despacho manuscrito aposto ao próprio documento. $\mathrm{O}$ autor do memorando, o então diretor do Departamento de Comunicações e Documentação, ressaltou que o Itamaraty não utilizava, até 
então, o termo ultrassecreto em seus arquivos.

Os documentos mais sensíveis recebiam o grau de "secreto-exclusivo". 0 memorando sugere que o ministério se preparasse para usar a nova nomenclatura e lembra que já vinha sendo adotada política de desclassificar automaticamente documentos de grau mais baixo de sigilo. Mas alerta que 0 acervo mais antigo guardado no Rio de Janeiro poderia conter informações que deveriam receber o grau de ultrassecreto. O mesmo memorando sugeriu que fosse constituído um grupo para a reclassificação de parte do acervo diplomático no Rio de Janeiro.

A lacuna nos registros arquivísticos identificados na presente pesquisa não permite saber se entre o final de 2008 e maio de 2009 foram produzidas novas versões do texto do projeto de lei da Lei de Acesso à Informação. $O$ governo federal não deixou, no entanto, de acompanhar de perto o processo de tramitação no Legislativo, após o envio de sua proposta aprovada somente em 2011.

\section{CONSIDERAÇÕES FINAIS}

A Lei de Acesso à Informação, criada sob o discurso de assegurar a ampla transparência na administração pública surgiu, como evidenciado, de um processo amparado na pressão da sociedade civil e num contexto internacional de proliferação de medidas legais para garantir ao cidadão o direito de se informar. Na esfera governamental federal, a iniciativa encontrou resistência principalmente de setores da administração pública que lidam com informações relacionadas à defesa nacional e as relações exteriores. A pesquisa documental realizada nos arquivos de órgãos da Administração pública federal indicou que o Comando do Exército foi o órgão que apresentou as objeções mais explícitas à ideia de criação de uma lei de acesso à informação.

No mesmo polo estava o Ministério das Relações Exteriores que, apesar de não registrar em documentos oficiais oposição ao envio de projeto ao Congresso Nacional, apresentou, nas reuniões de preparação do texto, restrições de mesma ordem às manifestadas pelas Forças Armadas. Os pontos 
mais polêmicos expressamente registrados nos registros arquivísticos foram as regras para classificação de documentos considerados sensíveis, incluindo as categorias de sigilo, o prazo de proteção de documento e a possibilidade ou não de perpetuação do sigilo por tempo indefinido.

\section{REFERÊNCIAS}

AERONÁUTICA. Ofício no 116, 2008.

BARROS, Dirlene Santos. A LEI BRASILEIRA DE ACESSO À

INFORMAÇÃO: Uma análise da sua construção, do contexto nacional ao contexto político oligárquico do estado do Maranhão (2009-2014). 2017. 238 f. Tese (Doutorado em Ciência da Informação) - Universidade de Brasília, Brasília, 2017. Disponível em: http://repositorio.unb.br/handle/10482/24009. Acesso: mar. 2019.

BRASIL. Lei 12.527 de 18 de novembro de 2011. Regula o acesso a informações previsto no inciso XXXIII do art. 5, no inciso II do $\S 3$ do art. $37 \mathrm{e}$ no $\S 2$ do art. 216 da Constituição Federal; altera a Lei 8.112, de 11 de dezembro de 1990; revoga a Lei 11.111, de 5 de maio de 2005, e dispositivos da Lei 8.159, de 8 de janeiro de 1991; e dá outras providências. Disponível em: http://www.planalto.gov.br/ccivil_03/_ato2011-2014/2011/lei//12527.htm. Acesso: 15 jun. 2017.

BRASIL. Câmara dos Deputados. PL 219/2003. Regulamenta o inciso XXXIII do art. $5^{\circ}$ da Constituição Federal, dispondo sobre prestação de informações detidas pelos órgãos da Administração Pública, 2003. Disponível em: http://www.camara.gov.br/proposicoesWeb/fichadetramitacao?idProposicao $=10$ 5237. Acesso em: ago. 2018.

BRASIL. Câmara dos Deputados. PL 5.228/2009. Regula o acesso a informações previsto no inciso XXXIII do art. $5^{\circ}$, inciso II do $\S 3^{\circ}$ do art. 37 e no $\S 2^{\circ}$ do art. 216 da Constituição, e dá outras providências. Disponível em: http://www.camara.gov.br/proposicoesWeb/fichadetramitacao?idProposicao $=43$ 4566. Acesso em: ago. 2018.

BRASIL. Senado Federal. PLC 041/2010. Regulamenta o inciso XXXIII do art. 5 o da Constituição Federal, dispondo sobre prestação de informações detidas pelos órgãos da Administração Pública, 2010. Disponível em: https://www25.senado.leg.br/web/atividade/materias/-/materia/96674. Acesso em: ago. 2018.

CGU. Processo 00190.009300/2007-49. Brasília, 2007. 
CHEN, Xiaowei. Some basic information on Freedom of Information in Sweden. 2017. Disponível em: https://se.okfn.org/2017/05/23/some-basicinformation-on-freedom-of-information-in-sweden/. Acesso em: 01 out. 2018.

COLLOR, Fernando. Parecer ao PLC 041/2010. Brasília, 2011. Disponível em: http://legis.senado.leg.br/sdleg-

getter/documento?dm=3948161\&disposition=inline. Acesso em: ago. 2018.

CUNHA FILHO, Márcio; XAVIER, Vítor César. Lei de Acesso à Informação: teoria e prática. Rio de Janeiro: Ed. Lumen Juris, 2014.

DUCHEIN, Michel. Obstacles to the Access, Use and Transfer of Information from Archives: A RAMP Study. Paris: Unesco, 1983. Disponível em: http://unesdoc.unesco.org/images/0005/000576/057672Eo.pdf. Acesso em: 21 out. 2018.

EXÉRCITO. Ofício 543-A/4-AL, 2008.

FONSECA, Francisco. A trama conflituosa das políticas públicas: Lógicas e projetos em disputa. Cad. EBAPE.BR, Rio de Janeiro, v. 14, número especial, 2016. DOI: http://dx.doi.org/10.1590/1679-395162646. Acesso em: 25 ago. 2018.

GIL, Antonio Carlos. Métodos e técnicas de pesquisa social. São Paulo: Ed. Atlas, 2008.

JARDIM, José Maria. A implantação da lei de acesso à informação pública e a gestão da informação arquivística governamental. Liinc Em Revista, Brasília, v. 2, n. 9, 2013.

MARINHA. Parecer no 52, 2008.

MICHENER, Gregory; MONCAU, Luiz Fernando Marrey; VELASCO, Rafael. Estado brasileiro e Transparência: avaliando a aplicação da lei de acesso à informação. Rio de Janeiro: Fundação Getúlio Vargas, 2015.

MEIJER, Albert. Transparency. In: BOVENS, Mark; GOODIN, Robert E.; SCHILLEMANS, Thomas. The Oxford Handbook of Public Accountability. Oxford: Oxford University Press, 2014. Disponível em: https://www.oxfordhandbooks.com/view/10.1093/oxfordhb/9780199641253.001. 0001/oxfordhb-9780199641253-e-043. Acesso em: abr. 2019.

MINISTÉRIO DA DEFESA. Processos 60150.000829/2007-03, volumes 1 e 2, 60430.000196/2008-60 e 60041.000083/2008-48, Brasília, 2007-2008.

MINISTÉRIO DA JUSTIÇA. Processo 08027000212/2006-02, Brasília, 2006. MINISTÉRIO DAS RELAÇÕES EXTERIORES. Memorando n 37, 2008. 
NASCIMENTO, S. dos S.; RODRIGUES, G. M.; KRAEMER, L. A utilização da Lei de Acesso à Informação pela imprensa: análise dos jornais Folha de $S$.

Paulo, O Estado de S. Paulo e O Globo. RuMoRes, [S. I.], v. 9, n. 18, p. 225248, 2015. Disponível em:

http://www.revistas.usp.br/Rumores/article/view/97261. Acesso em: 25 ago. 2017.

ÖBERG, Ulf. L'exemple suédois. In : Transparence et secret. Colloque pour le XXVème anniversaire de la loi du 17 juillet 1978 sur l'accès aux documents administratifs, 2003. Disponível em:

http://www.cada.fr/IMG/pdf/transparence.pdf. Acesso em maio de 2008.

OLIVEIRA JUNIOR, Temístocles Murilo; MONTEIRO, Cristiano Fonseca. Political Dynamics of Policy Transfer of Freedom of Information: The Study of the Brazilian Case. In: ANNUAL CONFERENCE IRSPM, 22., 2018. Anais [...]. Edinburgh, UK: [S.I.], 2018.

ONU. Declaração de Direitos Humanos, 1948. Disponível em:

https://www.ohchr.org/EN/UDHR/Pages/Language.aspx?LangID=por. Acesso em novembro 2018.

PAES, Eneida Bastos. A construção da Lei de Acesso à Informação Pública no Brasil: desafios na implementação de seus princípios. Revista do Serviço Público, Brasília, n. 62, v. 4, p. 407-423, out./dez., 2011. Disponível em https://repositorio.enap.gov.br/bitstream/1/1597/1/A\%20constru\%C3\%A7\%C3\% A30\%20da\%20Lei\%20de\%20Acesso\%20\%C3\%A0\%20Informa\%C3\%A7\%C3 $\%$ A30\%20P\%C3\%BAblica\%20no\%20Brasil\%20desafios\%20na\%20implementa $\%$ C3\%A7\%C3\%A30\%20de\%20seus\%20princ\%C3\%ADpios.pdf. Acesso em: 23 set. 2020.

PÁDUA, Elisabete Matallo Marchesini de. Metodologia da Pesquisa: Abordagem teórico-prática. 17. ed. Campinas: Papirus Editora, 2012.

RODRIGUES, Georgete Medleg. Legislação de Acesso aos Arquivos no Brasil: Um terreno de disputas políticas pela memória e pela história. Acervo, Rio de Janeiro, v. 24, n. 1, p. 257-286, jan/jun, 2011. Disponível em:

http://pfdc.pgr.mpf.mp.br/atuacao-e-conteudos-de-apoio/publicacoes/acesso-ainformacao/legislacao-de-acessoaos-arquivos-no-brasil-um-terreno-dedisputas-politicas-pela-memoria-e-pela-historia-georgete-medleg-rodrigues. Acesso em: 18 out. 2018.

RODRIGUES, Georgete Medleg. Memória e segredo na sociedade da informação: a simbologia do caso Herzog. In: ENCONTRO NACIONAL DE PESQUISA EM CIÉNCIA DA INFORMAÇÃO, 8., 2007, Salvador. Anais [...]. Salvador: UFBA, 2007.

RTI. Rating. Disponível em: http://www.rti-rating.org. Acesso em: 10 jun. 2018. 


\title{
BETWEEN SECRECY AND TRANSPARENCY: ANALYSIS OF THE ELABORATION PROCESS OF THE BRAZILIAN FREEDOM OF INFORMATION ACT IN THE FEDERAL GOVERNMENT (2006-2009)
}

\begin{abstract}
Introduction: The Brazilian Freedom of Information Act (LAI) was developed based on discussions within the scope of the Federal Executive Branch between the years 2006 and 2009. The text was the result of a confrontation between divergent positions on the scope and the extent of transparency that was intended to be achieved. Objective: To identify and analyze the position of different public agents, within the scope of the federal executive branch, regarding certain aspects of LAI seeking, in this perspective, to understand the process of internal discussion, identifying the sectors most inclined to secrecy and those most associated with transparency. Methodology: The methodological procedures included the modality of documentary research of archival records from the federal government. Results: Archival records of government sectors were identified with restrictions on the proposal for a new access law. It was found that the Army Command was the branch that presented the most explicit objections to the idea of creating a law on access to information, as well as the Ministry of Foreign Affairs. Conclusions: The LAI project met with resistance mainly from sectors of public administration that deal with information related to national defense and foreign relations. The most controversial points were the rules for classification of documents considered sensitive, including categories of confidentiality, the term of protection and the possibility or not of perpetuation of confidentiality for an indefinite period.
\end{abstract}

Descriptors: Freedom of Information Act. Public Transparency. Secrecy. Federal government.

\section{ENTRE SIGILO Y TRANSPARENCIA: ANÁLISIS DEL PROCESO DE ELABORACIÓN DE LA LEY DE ACCESO A LA INFORMACIÓN EN EL GOBIERNO FEDERAL (2006- 2009)}

\begin{abstract}
RESUMEN
Introducción: Poder Ejecutivo Federal entre los años 2006 y 2009. El texto fue el resultado de la confrontación entre posiciones divergentes sobre el alcance y el grado de transparencia que se pretendía lograr. Objetivo: identificar la posición de los agentes públicos, dentro del ámbito del poder ejecutivo federal, con respecto a aspectos de LAI, buscando comprender el proceso de discusión interna, identificando los sectores más inclinados al secreto y los más asociados con la transparencia. Metodología: Los procedimientos metodológicos incluyeron la modalidad de investigación documental de registros de archivo del gobierno federal. Resultados: Se identificaron los registros de archivo de los sectores gubernamentales con restricciones en la propuesta para una nueva ley sobre el acceso. Se descubrió que el Comando del Ejército era el organismo que presentaba las objeciones más explícitas a la idea de crear una ley sobre el acceso a la información, así como el Ministerio de Relaciones Exteriores. Conclusiones: El
\end{abstract}


proyecto LAl encontró resistencia principalmente de los sectores de la administración pública que se ocupan de información relacionada con la defensa nacional y las relaciones exteriores. Los puntos más controvertidos fueron las reglas para la clasificación de documentos considerados sensibles, incluidas las categorías de confidencialidad, el plazo de protección y la posibilidad o no de perpetuar la confidencialidad por un período indefinido.

Descriptores: Ley de Libertad de Información. Transparencia Pública. Sigilo. Gobierno federal.

Recebido em: 12.02.2020

Aceito em: 26.10.2020 